\title{
Faculty Members' Perspective on Virtual Interviews for Medical Residency Matching during the COVID-19 Crisis: A National Survey
}

\author{
Fadi Aljamaan a,b*, Fadiah Alkhattabi ${ }^{\mathrm{c},}$, Ayman Al-Eyadhy a,d, Ali Alhaboob a,d, Nasser Alharbi a,d, Adi Alherbish ${ }^{\mathrm{a}, \mathrm{d}}$, \\ Badr Almosned d, Mohamad Alobayland, Hayfa Alabdulkarim d, Amr Jamal a,e,f, Sami A. Alhaider g, Basim Alsaywid

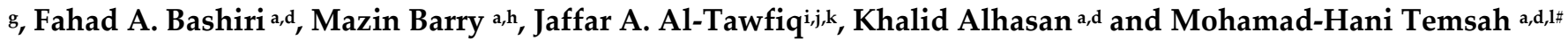

a College of Medicine, King Saud University, Riyadh, Saudi Arabia; faljamaan@ksu.edu.sa; aalherbish@ksu.edu.sa; amrjamal@ksu.edu.sa; fbashiri@ksu.edu.sa ; mbarry@ksu.edu.sa ; kalhasan@ksu.edu.sa; mtemsah@ksu.edu.sa

b Critical Care Department, King Saud University Medical City, Riyadh, Saudi Arabia

c King Faisal Specialist Hospital and Research Center, Riyadh, Saudi Arabia;FKhatabi@kfshrc.edu.sa

d Pediatric Department, King Saud University Medical City, Riyadh, Saudi Arabia; balmosned@ksu.edu.sa; Mohammed.alobaylan@gmail.com; hayfa.alabdulkarim@gmail.com

e Department of Family and Community Medicine, King Saud University Medical City, Riyadh, Saudi Arabia

f Evidence-Based Health Care \& Knowledge Translation Research Chair, King Saud University, Riyadh, Saudi Arabia

g Saudi Commission For Health Specialties, Riyadh, Saudi Arabia; S.alhaidar@ scfhs.org; drbasim@yahoo.com

h Division of Infectious Diseases, Department of Internal Medicine, King Saud University Medical City, Riyadh, Saudi Arabia

i Specialty Internal Medicine and Quality Department, Johns Hopkins Aramco Healthcare, Dhahran, Saudi Arabia

j Infectious Disease Division, Department of Medicine, Indiana University School of Medicine, Indianapolis, IN, USA

k Infectious Disease Division, Department of Medicine, Johns Hopkins University School of Medicine, Baltimore, MD, USA

1 Prince Abdullah Ben Khaled Coeliac Disease Chair, Faculty of Medicine, King Saud University.

* Equally contributed

\# Correspondence to:Dr Mohamad-Hani Temsah, Pediatric Department, College of Medicine, King Saud University, PO Box 14135 Riyadh 11424, mtemsah@ksu.edu.sa, Riyadh, Saudi Arabia

\begin{abstract}
During the COVID-19 pandemic, conducting face-to-face medical residency interviews was challenging due to infection prevention precautions, social distancing and travel restrictions. Virtual interviews were implemented by the Saudi Commission for Health Specialties (SCFHS) as an alternative process for residency matching while striving to maintain the same quality standards. This national survey was conducted to assess the satisfaction and perceptions of faculty members' virtual interviews performance in the assessment for the medical training residency programs. Among the participating 173 faculty members (34.1\%) did not have previous experience with videoconferencing. Zoom application was the most commonly used platform (65.9\%). Most (89.6\%) of the faculty perceived virtual interviews as "adequate" for the candidates to express themselves, while almost half of the faculty (53.8\%) agreed that virtual interviews allowed them to accurately reach an impression about the candidates. Overall, $73.4 \%$ of faculty felt comfortable ranking the virtually interviewed candidates. We conclude that the acceptance of participating faculty members in the first Saudi medical residency training matching cycle virtual interviewing event was well perceived. This study provides evidence for future application and research of virtual interviews in residency candidates' assessment, especially after the pandemic crisis resolves.
\end{abstract}

Keywords: COVID-19; medical residency; virtual interviews; satisfaction; survey; faculty member 


\section{Background:}

The process of the application for medical training program constitutes a series of steps that culminate with personal interview. The interview is usually the last step of securing the slot. Data from human resources show that once candidates are selected for interviews based on their curricula vitae or application forms, they are mostly at the same level on the competing platform[1]. In fact, interviews yield several pieces of information regarding applicants that would not be extracted from their resumes or personal statement, and are a chance for the interviewee to explore the institution. Interviews aim primarily to assess the candidates' communication skills, in addition to exploring their aptitude, facial expressions, fluency, and certain clinical as well as ethical skills. Finally, interviews allow the assessment of the candidate for any red flags that would hinder their acceptance.

Program directors have reported that interviews are the key step in selecting candidates[2,3]. On the other hand interviews have been criticized for being biased due to failure of standardization in many instances and low interviewer reliability and reproducibility[4-6].

Interviews have been conducted for a long time through the classical method of onsite face to face platform. That method has been encouraged owing to the advantage of such interaction with its intangible benefits. However, these classic ways of interviews have been criticized for multiple flaws, mainly the high cost for both parties[7], and unfair competence among candidates if they are financially challenged [8] or those with scheduling conflicts with limited interviewing slots, and clinical work disruption [9]. As technology is one of the main enhancers of modern healthcare systems, adopting new trends in technology is crucial to align them and optimize their utilization in healthcare services and medical training [10]. Therefore there has been a trend in the last decade towards video conferencing interviews.

The coronavirus disease 2019 (COVID-19) pandemic that is caused by the severe acute respiratory syndrome coronavirus 2 (SARS-CoV-2) coincided with the of application process of the postgraduate medical specialties training programs in the Kingdom of Saudi Arabia. Thus, when COVID-19 was declared by the World Health Organization (WHO) as a pandemic in March 2020, this mandated exploring new dimensions in medical training interviewing and teaching [11] [12]. The Saudi Commission for Health Specialties (SCFHS) is the national regulator of postgraduate medical training in Saudi Arabia, that involves application, nomination, interviewing, matching, supervising and assessing healthcare training programs, qualifying trainees and setting standards for the practice and development of health professions; issuing registration and professional classification certificates for all healthcare practitioners in Saudi Arabia. Facing the challenge of infection prevention practices (social distancing and crowd avoidance) during the pandemic, SCFHS decided to substitute onsite face-to-face interviews with virtual interviews in compliance with the different mitigation measures, especially that both (faculty members and applicants) are healthcare workers who may pose potential risk of spreading SARS-CoV2 to different health institutions.

Several studies have evaluated virtual interviews in medical and surgical training programs, but most were individualized for one program and conducted in a single center, in addition the virtual interviews were offered as an option or adjunct to the traditional face-to-face interview $[13,14]$. Most studies have concluded that virtual interviews can be a cost-effective and efficient alternative for on-site in-person interviews [7,13-15]. As a , still being a newly introduced method, it has been faced by criticism and questionable validity and acceptability by both applicants and faculty members. There is a growing need for studies to evaluate the performance of virtual interviewing system and its implementation in the medical residency program keeping in mind what has been said regarding the importance of it in the final decision of trainee choice and its consequences. Thus, this study was conducted to assess faculty members' satisfaction, acceptance, and 
perception of virtual interviews performance from different aspects that have been conducted by SCFHS for the Matching-cycle of March 2020 during the COVID-19 pandemic.

\section{Methods:}

For the March 2020 SCFHS matching cycle, faculty members for the residency programs were surveyed for their satisfaction, perception of the virtual interviews performance from different domains regarding applicant evaluation, audiovisual quality, applications used, preparation, event associated stress, and others, with Likert scales (Appendix $1)$.

\section{Sampling technique:}

A non-probability, consecutive sampling technique was implemented. An invitation to participate in the survey was sent to all faculty members who participated in the virtual interviews for matching cycle of March 2020.

\section{Survey tool validation:}

The tool was developed based on a literature review by an expert panel, and a pilot study involving ten candidates was conducted to validate the tool for clarity and consistency. The questionnaires were sent electronically to the participants within four weeks of the virtual interviews (April 15-30, 2020), with reminders for non-responders after two days.

\section{Data analysis:}

The means and standard deviations (SDs) were used to describe continuous variables, and categorical variables were presented as frequencies and percentages. The statistical normality assumption was examined using histograms and the KolmogorovSmirnov statistical test, and the statistical equality of the variance assumption was assessed using Levene's test.

Cronbach's alpha test of reliability was performed to assess the internal consistency of the Likert-based items characterizing different concepts. Besides, a multiple-response dichotomy analysis was performed to describe the frequencies and percentages of the tickall-that-applies questions. The overall mean scores of the Perceived Stress Scale and Perceived Satisfaction Scale with videoconferencing were computed by adding the items comprising these concepts and dividing the sum by the number of items for each concept. Statistical Package for the Social Sciences (version 21; IBM Corp., Armonk, NY, USA) was used for all statistical data analyses, and $p$-values of less than 0.050 denoted statistical significance.

\section{Ethical approval:}

This study was conducted on the rapid utilization of videoconference interviews in the residency application process was in accordance with the postgraduate center recommendations (memo \# 9/3/311082) This study had the approval of the SCFHS's Institutional Review Board (\# 0420-03 exp). Data were collected after the participants have provided their informed consent. Participation was voluntary and not linked to the applicants' evaluation. The results of this study will be used as a quality improvement project of the SCFHS.

\section{Results:}

173 faculty members completed the survey. Considering their specialties, $23.1 \%$ were pediatricians, $(14.5 \%)$ surgeons, $(12.1 \%)$ from obstetrics and gynecology. The other specialties contribution ranged between 1.2 and $5.8 \%$ (Figure 1). The members split equally 
in their years of practice as consultant/faculty members: less than 5 years, more than 10 years or in between (Table 1 ).

Regarding the results of their previous experience with video conferencing $(63 \%)$ mentioned they had but didn't use it for residency interviews, while $(2.9 \%)$ did, and (34.1\%) didn't have previous video conferencing experience at all (Table1).

The faculty members were given the support to use multiple video conferencing software programs during the current virtual interviewing event including Facetime, Zoom, or another interface. Most of the interviews were based on Zoom (65.9\%) all through, $(9.8 \%)$ used mostly Facetime but rarely Zoom, while $(0.6 \%)$ used Facetime all through the interviews (Figure 2). About $55 \%$ of the faculty members chose the video conferencing software based on their personal preference and for being user-friendly, while (32.9\%) chose it based on a colleagues' advice (Figure 3 ).

Regarding the faculty members' perception of the virtual interviews' performance, $(89.6 \%)$ agreed or strongly agreed that they were adequate for the candidates to properly answer questions and express him/herself, while (5.2\%) were neutral, and the remaining did not think it was adequate. On the other hand, $(65.4 \%)$ agreed or strongly agreed that the virtual interviews allowed them to accurately reach an impression about the applicant personality, while $(17.9 \%)$ were neutral and $(16.8 \%)$ were on the negative side.

Overall, most of the faculty members felt comfortable to rank the interviewed candidates based on the virtual interviews $(73.4 \%)$ while $(14.4 \%)$ disagreed or strongly disagreed (further details are shown in Table1).

\section{Faculty members speciality in \%}

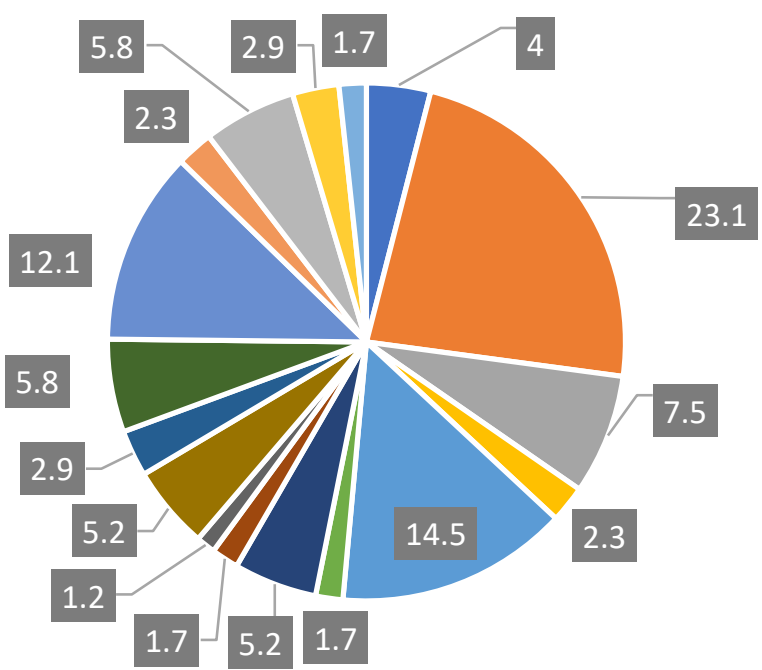

\begin{tabular}{|c|c|c|}
\hline - Other (please specify) & - Pediatrics & Family medicine \\
\hline - Internal medicine & - Surgery & Emergency medicine \\
\hline - Psychiatry & - Pharmacological & - Urogenitary \\
\hline - Radiology & - Pathology & - Dentistry \\
\hline - Obsterics \& Gynacology & - Neurology/surgery & Critical care \\
\hline Dermatology & - Opthamlmology & \\
\hline
\end{tabular}

Figure 1 
Table 1: Descriptive analysis of the faculty members' experience and perceptions of virtual interviews performance.

\begin{tabular}{|c|c|c|}
\hline & Frequency & Percentage \\
\hline \multicolumn{3}{|l|}{ Years of practice as a consultant/faculty member } \\
\hline less than 5 years & 52 & 30.1 \\
\hline $5-10$ years & 52 & 30.1 \\
\hline More than 10 years & 69 & 39.9 \\
\hline \multicolumn{3}{|c|}{ Prior to this Video Interview, did you have prior experience in this tool? } \\
\hline No, my first time to use video conferencing & 59 & 34.1 \\
\hline $\begin{array}{l}\text { Yes I used video conferencing before, but first time to use } \\
\text { it for residency interview }\end{array}$ & 109 & 63 \\
\hline $\begin{array}{l}\text { Yes I used video conferencing before, including for resi- } \\
\text { dency interview }\end{array}$ & 5 & 2.9 \\
\hline \multicolumn{3}{|l|}{ The video-conferencing electronic Device used } \\
\hline PC (laptop) & 104 & 60.1 \\
\hline PC (Desk top) & 19 & 11 \\
\hline Mobile & 50 & 28.9 \\
\hline \multicolumn{3}{|c|}{ The interview allowed me to accurately reach an impression of the applicant's personality } \\
\hline Strongly disagree & 15 & 8.7 \\
\hline Disagree & 14 & 8.1 \\
\hline Neither agree or disagree & 31 & 17.9 \\
\hline Agree & 93 & 53.8 \\
\hline Strongly agree & 20 & 11.6 \\
\hline \multicolumn{3}{|l|}{ My questions for the candidates were answered } \\
\hline Strongly disagree & 7 & 4 \\
\hline Disagree & 2 & 1.2 \\
\hline Neither agree or disagree & 9 & 5.2 \\
\hline Agree & 97 & 56.1 \\
\hline Strongly agree & 58 & 33.5 \\
\hline \multicolumn{3}{|c|}{ I felt comfortable ranking the candidates based on the virtual interviews } \\
\hline Strongly disagree & 13 & 7.5 \\
\hline Disagree & 12 & 6.9 \\
\hline Neither agree or disagree & 21 & 12.1 \\
\hline Agree & 80 & 46.2 \\
\hline Strongly agree & 47 & 27.2 \\
\hline
\end{tabular}




\section{Video conferencing tools used by faculty members}

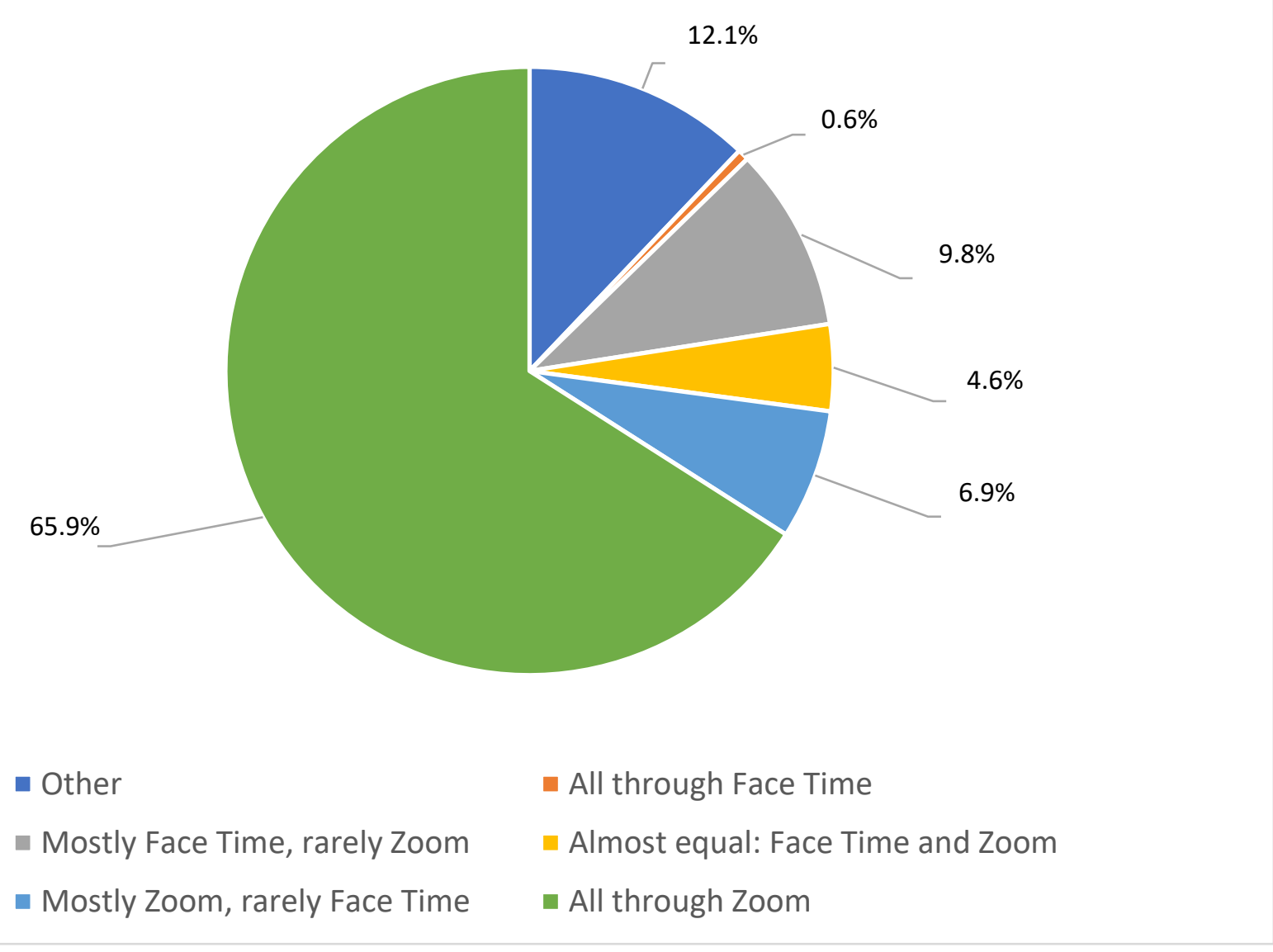

Figure 2 


\section{Faculty members' motive of video conferencing tools choice}

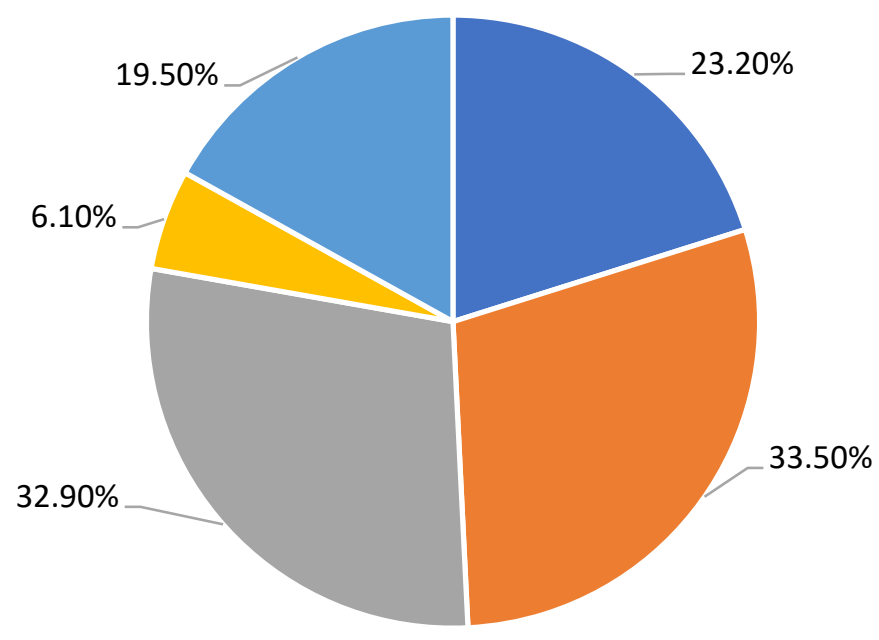

- My own personal preference (example: previous experience with Zoom or Face Time

- The ease of use (user-friendly) of the App

- My colleague's advice

- My mobile operating system (Apple versus Android-based)

\section{Figure 3}

Participating faculty members had an overall high satisfaction with virtual interviews experience as their recommendation for its future use, with a mean rating of 8.37/10 (1.50) (SD). Regarding the faculty members' perception of the interviews organization and performance; $(87.3 \%)$ felt all or most of the information was given pre event, while only $(10.4 \%)$ felt some information was given. Considering stress level perceived by the faculty members during the virtual interviews: $(42.2 \%)$ felt only slightly stressed, $(24.9 \%)$ felt moderately stressed, (21.4\%) did not feel any stress at all and while only $(16.5 \%)$ felt very stressed (Figure 5). Event organization: Majority (88.3\%) felt that it was extremely or very organized and $(10.4 \%)$ only felt that it was somewhat organized. Duration of the interviews: Majority $(86.7 \%)$ felt that it was just the right duration.

Regarding their satisfaction with the virtual interviews video and voice quality, time and place flexibility all scored higher than 4 out of 5 (Figure 4)

Their overall rate for the event was (4.16 out of 5 SD 0.89$)$, (41.6\%) felt that the event was excellent, ( $38.2 \%)$ felt that it was very good, while only $(0.6 \%)$ felt it to be poor (Figure $6)$.

The faculty members showed high preference to recommend virtual interviews to their colleagues (8.37/10 SD 1.50 on Likert scale), but when asked about their preference to use them in the future versus face to face interviews; $(49.7 \%)$ of them preferred virtual interviews, $(24.9 \%)$ preferred face-to-face, and the remaining were neutral for both ( Figure 7). 
Table 2: Faculty members' indicators of satisfaction with virtual interviews.

\begin{tabular}{|c|c|c|}
\hline Indicator & Frequency & Percentage \\
\hline \multicolumn{3}{|c|}{ Prior to the event, how much of the information that you needed did you get? } \\
\hline All of the information & 63 & 36.4 \\
\hline Most of the information & 88 & 50.9 \\
\hline Some of the information & 18 & 10.4 \\
\hline A little of the information & 4 & 2.3 \\
\hline \multicolumn{3}{|l|}{ How organized was the event? } \\
\hline Extremely organized & 74 & 42.8 \\
\hline Very organized & 79 & 45.7 \\
\hline Somewhat organized & 18 & 10.4 \\
\hline Not so organized & 2 & 1.2 \\
\hline \multicolumn{3}{|c|}{ Was the event length too long too short or about right? } \\
\hline Much too long & 3 & 1.7 \\
\hline Too long & 12 & 6.9 \\
\hline About right & 150 & 86.7 \\
\hline Too short & 8 & 4.6 \\
\hline \multicolumn{2}{|l|}{ Indicator } & Mean, (SD) \\
\hline \multicolumn{2}{|c|}{ How stressed were you during the Video Interview. } & $2.33 / 5(1.1)$ \\
\hline \multicolumn{2}{|c|}{ Overall, how would you rate the event. } & $4.16 / 5(0.89)$ \\
\hline \multicolumn{2}{|c|}{ How likely is it that you would recommend virtual interviews to a colleague } & $8.37 / 10(1.50)$ \\
\hline
\end{tabular}




\section{Faculty members' (mean) satisfaction rate with virtual interviews domains of performance (maximum 5)}

5

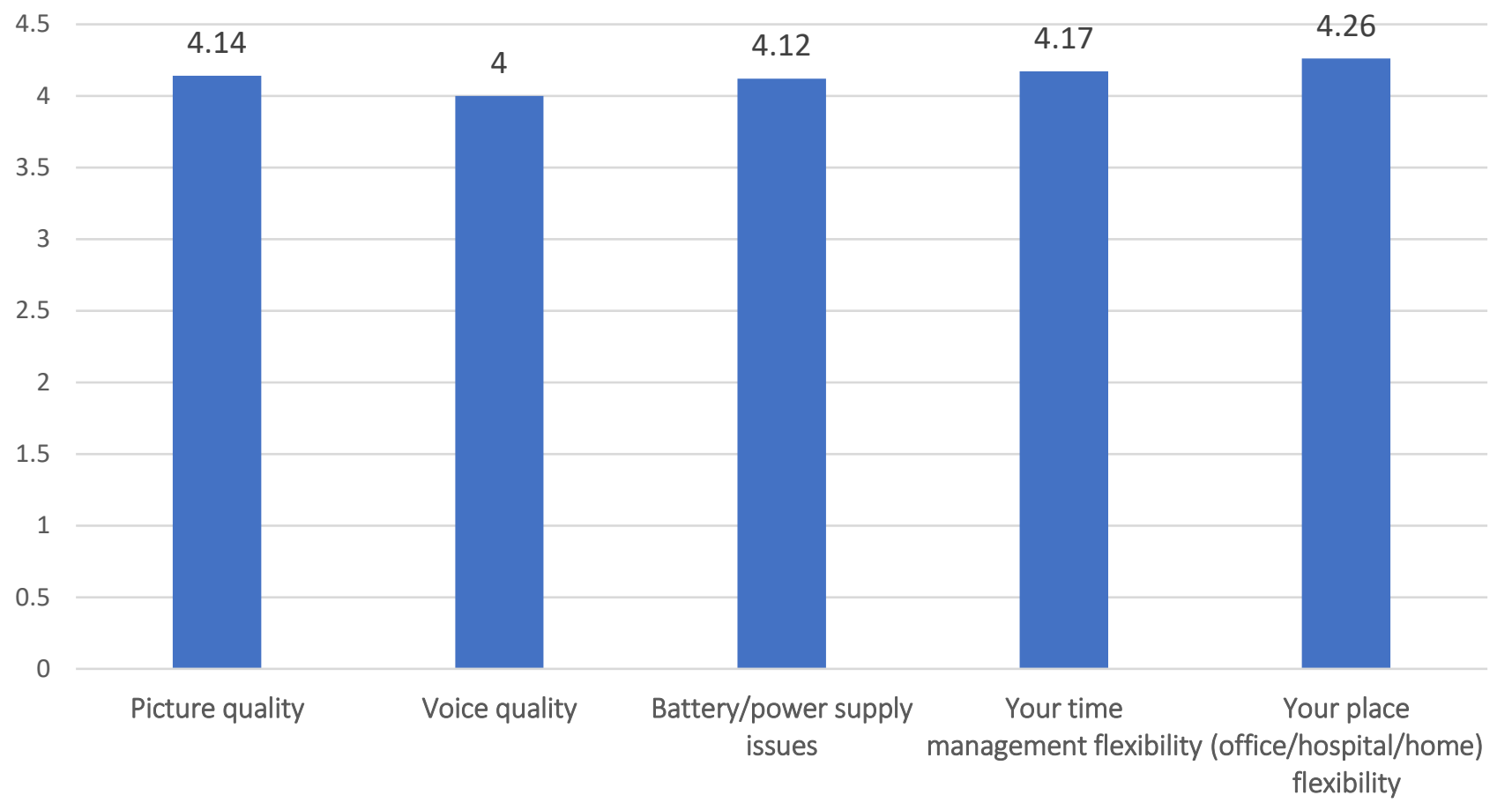

Figure 4

Stress level perceived by the faculty members

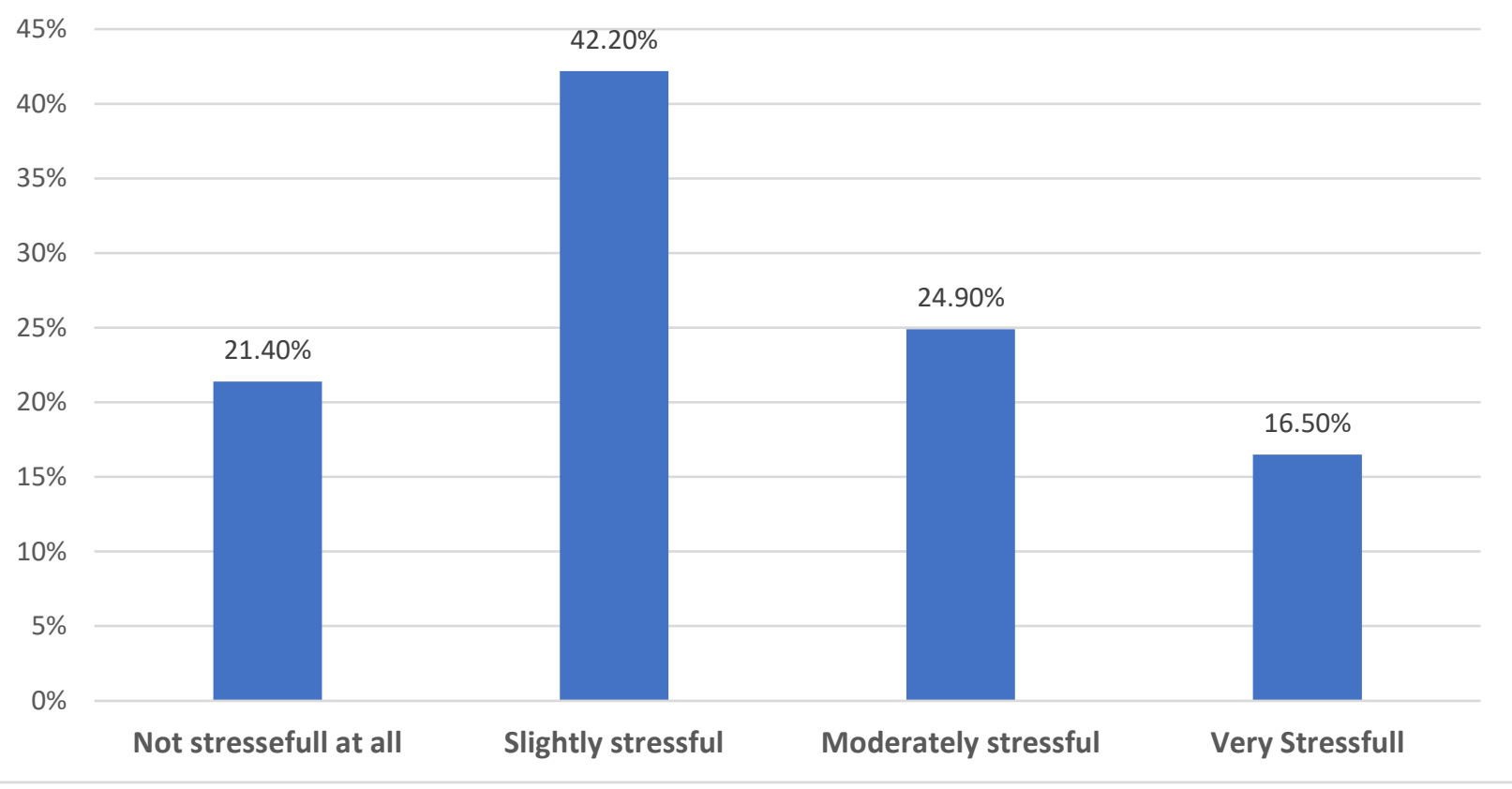

Figure 5 


\section{Faculty members overall rating of the virtual interview experience}

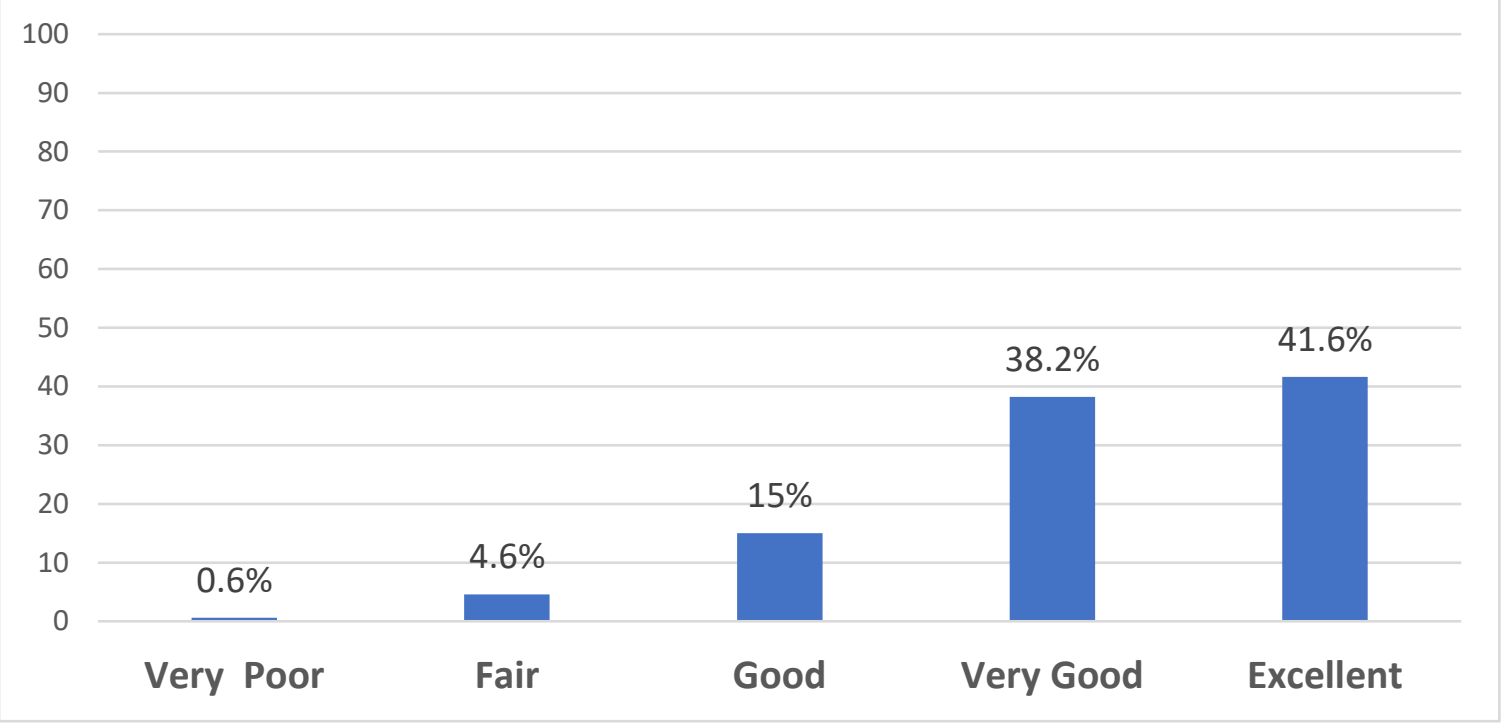

Figure 6

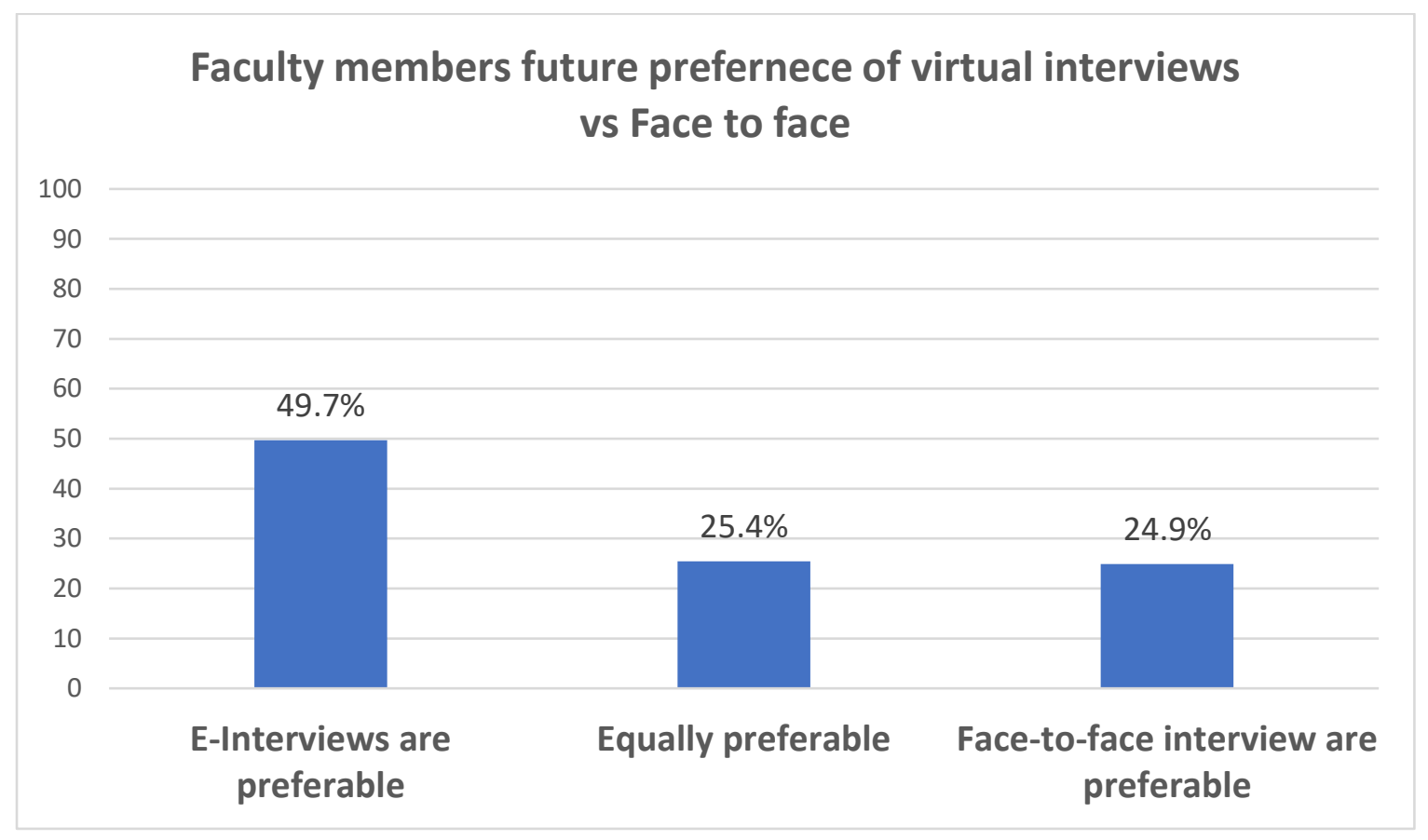

\section{Figure 7}

We also surveyed the faculty members for the different factors that they perceived may have enhanced or negatively affected the residents' virtual interview experience. The majority $(65.3 \%)$ believed that organizers' communication was the most important enhancer followed by the optimal internet connection speed (55.5\%), followed by clear instructions $(43.4 \%)$ and that the video conferencing software is free of charge $(40.5 \%)$. 
Regarding the negative impactors, (59.5\%) thought that internet connection speed was occasionally slow or was interrupted and that might have negatively affected the residents' experience, $(25.4 \%)$ felt that applicants were unfamiliar with video conferencing software, $(17.3 \%)$ expressed that a lack of a demonstrating video on how to use the tool prior to the event was a major negative impactor. For other enhancers and negative impactors refer to figures 8 and 9 .

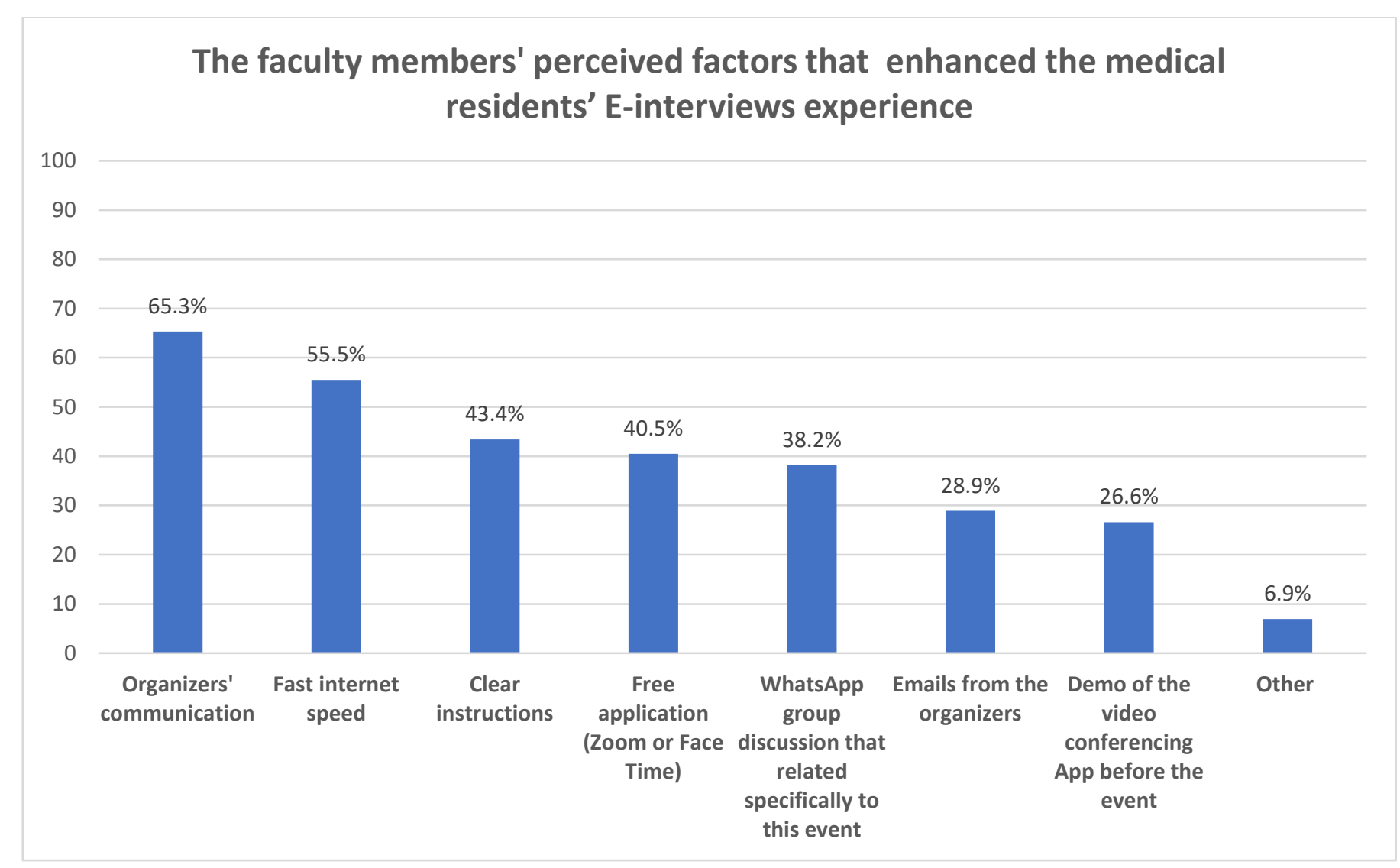

Figure 8 


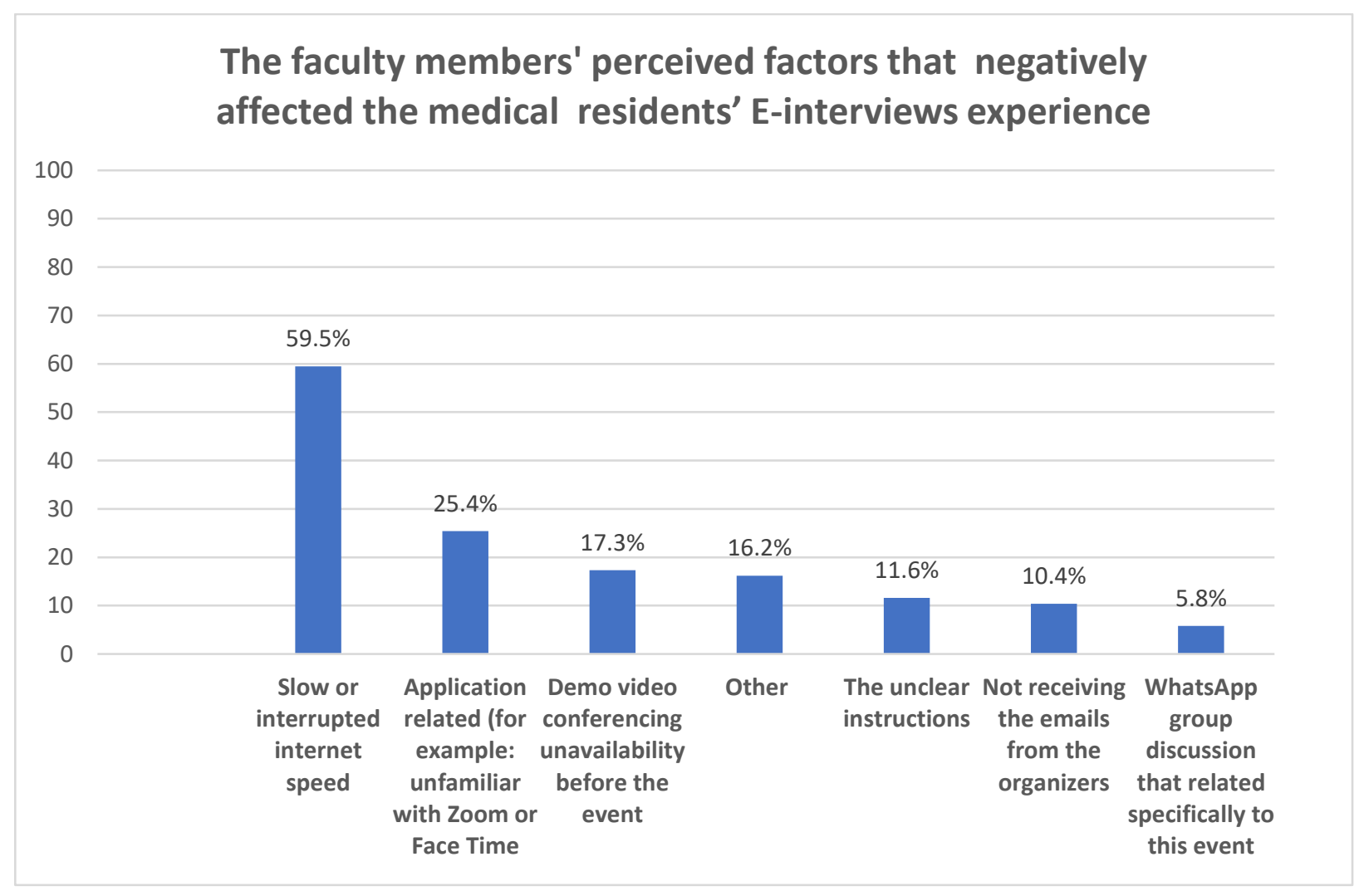

Figure 9 


\section{Discussion:}

Virtual interviews have been implemented for almost a decade in the medical residency and fellowship matching process. Many studies have been published worldwide to assess their performance and faculty and applicants satisfaction with them, however they have not been introduced in the matching system in Saudi Arabia before. When the COVID-19 pandemic affected Saudi Arabia in March 2020, different mitigation measures were implemented including lockdowns, prevention of gatherings, and travel restrictions[16-18]. These unique circumstances prompted the SCHS to introduce virtual interviews for the March 2020 cycle.

Our study aimed to survey the faculty members' experience with the Saudi's first virtual medical residency interviews. Our results have shown high faculty satisfaction with this experience, which matched the international literature even though the latter has been inconsistent in its results to some extent[19]. A recent Mayo Clinic study during the COVID-19 pandemic showed high satisfaction of program directors' (PD) with virtual interviews (Mean 4.65/5) which is similar to our result for all faculty members (4.16/5), however, in their study just over a half of all PD agreed or strongly agreed that next year's interviews should be virtual regardless of the COVID-19 status[20] Another study conducted during the COVID-19 pandemic addressed neurosurgery residency program virtual interviews and showed that $57 \%$ of faculty agreed to implement virtual interviews in the future while $44.5 \%$ expressed that they would not replace in-person interviews with virtual interviews in the future[21], both studies echoed our results as only $(49.7 \%)$ of the faculty members only preferred the virtual interviews in the future, and (24.9\%) preferred face-to-face interviews (figure 6). Another study during the pandemic that evaluated the cardiothoracic match for the year 2020 has shown reasonable PD satisfaction with virtual interviews as $55 \%$ of them agreed or strongly agreed that they should be offered in the future while only $15 \%$ of them agreed or strongly agreed that it should be offered without the option of in-person interview[19]. Thus, so far most evidence supports that faculty (members) and program directors have shown good satisfaction with virtual interviews but are still not fully confident to replace face-to-face interviews with virtual interviews in the future. One study explored the lack of trust in virtual interviews, it showed that $50 \%$ of PDs suggested that virtual interviews made the selection committee rely much more on the applicant objective data rather than the interview itself, $75 \%$ and $67 \%$, respectively, disagreed or strongly disagreed that E-interviews allowed easier assessment of the applicant's fit, and personality and communication skills[22]. In contrast our study was highly encouraging from faculty point of view as $65.4 \%$ of the faculty members agreed or strongly agreed that virtual interviews allowed them to reach an impression about the applicants' personality, while (17.9\%) were neutral and (16.8\%) were unsatisfied, $73.4 \%$ felt comfortable to rank candidates based on the perceived impression, (89.6\%) agreed or strongly agreed virtual interviews were adequate for candidates to answer different questions and properly express themselves. In comparison, a recent local study that assessed applicant's satisfaction with virtual interviews showed that only $37.3 \%$ and $14.9 \%$ agreed or strongly agreed, respectively that the interview allowed them to accurately represent themselves, while $63.3 \%$ would prefer virtual interviews over face-to-face interviews in the future[23].

In our study the faculty members had variable trust of some assessment domains regarding the virtual interviews, may be magnified when we compare the faculty high satisfaction of virtual interviews performance of almost $90 \%$, while only $(73.4 \%)$ felt comfortable to rank the interviewed candidates based on these interviews. On the contrary, only $(53.8 \%)$ agreed that the virtual interviews allowed them to accurately establish a proper assessment about the applicant's personality, although this may seem contradictory to the results, this may point to certain defects in the performance or the assessment process that our study, similar to others, could not examine further, which culminated with the faculty perception when asked about their future preference between virtual 
interviews and traditional face to face interviews, $(49.7 \%)$ only preferred the virtual interviews, while $(24.9 \%)$ preferred face-to-face interviews.

The majority of our involved faculty members $(63 \%)$ have used video conferencing tool previously especially with the current COVID-19 pandemic and the wide applicability of such tools for administrative meetings, webinars, clinical based meeting, this created familiarity with digital technology and their healthcare and medical education application, this has been reflected clearly on their low stress level as about $80 \%$ felt slightly stressed or not stressed at all with the virtual interview process.

Virtual interviews organization, telecommunication quality , and the interviews setting pliability, are crucial items to be addressed when introducing digital videoconferencing in residency matching process. Our literature review revealed lack of data pertaining to performance domains of the virtual interviews. One of the strengths of our study is that we explored the faculty members' perception of the interviews performance regarding their quality indicators from different points, and their pliability for usage in term of place and time which showed decent satisfaction results[24,25].

Such virtual experience being newly introduced worldwide and especially here in Saudi Arabia needs to be fortified and developed each matching cycle, areas of improvement could be introducing virtual tours in training centers, didactic training courses highlighting the pearls and challenges of each residency program helping the applicants to focus their decision compass.

Virtual interviewing is the future of medical training matching process, it started before the current COVID-19 pandemic and progressed quickly since then. Satisfaction with its performance has been variable so far. It will still need improvements in different domains, preparation, investment in digital technology, assuring equal affordability to all applicants, development of standard validated virtual assessment tools and continuous feedback and assessment of its performance. The current results of our first Saudi virtual interviewing experience have been encouraging and they would be an aid for organizers of future events to consider areas of improvements. Future research that compares both types of interviews, both virtual and physical, with comparison groups or case-control study would explore the full potentials, and what are the pros and cons for each interview style.

\section{Study limitations:}

While our study explores a newly implemented virtual interviews system for the first virtual interviewing process of the national medical residency matching in the region, it has some limitations. The self-reported nature of surveys carries potential recall bias. We did not assess the perception of program directors specifically as a subgroup of the rest of faculty members. We could have addressed more detailed dimensions of candidates' virtual assessment standards and tools to dissect more the performance of the virtual interviews. Also, our study was a single-arm survey, as only virtual residency-matching interviews were conducted during the COVID-19 crisis in Saudi Arabia, and we did not find historical data or previous survey in Saudi Arabia to compare as another arm.

\section{Conclusion:}

This study shows encouraging results pertaining to virtual interviews, as an established and acceptable tool for medical residency matching and need ongoing improvement and assessment. Identified areas that need improvement include internet connection and lack of demonstration videos pre-interviews. Further research could explore how coping with the modern technology trends can promote the quality and efficacy of residency training programs virtual interviews. 


\title{
Declarations:
}

Ethics approval and consent to participate: The Institutional Review Board of the Saudi Commission for Healthcare Specialties approved the study, Riyadh, Saudi Arabia (IRB approval code 042003). Electronic informed consent was obtained from all the participants. We confirm that all methods were carried out in accordance with relevant guidelines and regulations.

Consent for publication: Not applicable.

Availability of data and materials: All data in this study will be made available upon reasonable request by directly contacting Dr. Mohamad-Hani Temsah at mtemsah@ksu.edu.sa

Competing interests: None declared.

Funding: This research has been financially supported by Prince Abdullah Ben Khalid Celiac Disease Research Chair, under the Vice Deanship of Research Chairs, King Saud University, Riyadh, Kingdom of Saudi Arabia.

Authors' contributions: MHTem, FAlj, FAlk, KAlh, and BAls conceptualized the study, analyzed the data, and wrote the manuscript. BAlm, MAlo, HAla, and AJam contributed to the study design; collected, analyzed, and interpreted the data; and edited the manuscript. SAAlh contributed to the study design, interpreted the data, and edited the manuscript. FBas, AAle, AAlh, NAlh, and AAlh interpreted the data and finalized the manuscript. JAAlt and MBar critically appraised and revised the manuscript. All authors reviewed and approved the final version of the manuscript.

Acknowledgments: The research team is grateful to the Saudi Commission for Health Specialties (SCFHS), especially Ms. Sheroug Alhamoudi, and to Dr Mona Phelby for their valuable support. Also, we are thankful for the statistical data analysis consultation and support offered by www.hodhodata.com.

\author{
Abbreviations: \\ COVID-19: coronavirus disease 2019 \\ Virtual interview: electronic interview videoconferencing \\ SCFHS: Saudi Commission for Health Specialties \\ WHO: World Health Organizationtable
}

\section{References:}

1. Natarajan, A. What is the value of an interview? J R Soc Med 2007, 100, 57-58, doi:10.1177/014107680710000120.

2. Galazka, S.S.; Kikano, G.E.; Zyzanski, S. Methods of recruiting and selecting residents for U.S. family practice residencies. Acad Med 1994, 69, 304-306, doi:10.1097/00001888-199404000-00015.

3. Wood, J.S.; David, L.R. Outcome analysis of factors impacting the plastic surgery match. Ann Plast Surg 2010, 64, 770-774, doi:10.1097/SAP.0b013e3181b4bcf5.

4. Stephenson-Famy, A.; Houmard, B.S.; Oberoi, S.; Manyak, A.; Chiang, S.; Kim, S. Use of the Interview in Resident Candidate Selection: A Review of the Literature. J Grad Med Educ 2015, 7, 539-548, doi:10.4300/jgme-d-14-00236.1.

5. Clancy, A. Preventing illegal interview questions: the need for training skilled interviewers. In Acad Med; United States, 2014; Volume 89, p. 371.

6. Hern, H.G., Jr.; Alter, H.J.; Wills, C.P.; Snoey, E.R.; Simon, B.C. How prevalent are potentially illegal questions during residency interviews? Acad Med 2013, 88, 1116-1121, doi:10.1097/ACM.0b013e318299eecc.

7. Pourmand, A.; Lee, H.; Fair, M.; Maloney, K.; Caggiula, A. Feasibility and Usability of Tele-interview for Medical Residency Interview. West J Emerg Med 2018, 19, 80-86, doi:10.5811/westjem.2017.11.35167.

8. Kerfoot, B.P.; Asher, K.P.; McCullough, D.L. Financial and educational costs of the residency interview process for urology applicants. Urology 2008, 71, 990-994, doi:10.1016/j.urology.2007.11.102.

9. Burkhardt, J.C. What Can We Learn From Resident Selection Interviews? J Grad Med Educ 2015, 7, 673-675, doi:10.4300/jgme-d-15-00403.1.

10. Thimbleby, H. Technology and the future of healthcare. J Public Health Res 2013, 2, e28, doi:10.4081/jphr.2013.e28.

11. Organization, W.H. WHO Director-General's opening remarks at the media briefing on COVID-19 - 18 March 2020. Available online: https://www.who.int/dg/speeches/detail/who-director-general-s-opening-remarks-at-the-media-briefing-oncovid-19---18-march-2020 (accessed on 5 July 2020). SCFHS. Saudi Commission for Health Specialties 
Matching System Principles and Guidelines. Available online: https://www.scfhs.org.sa/MESPS/Documents/SCFHS-Eng-MS2020.pdf (accessed on 26 Jan 2021).

13. Daram, S.R.; Wu, R.; Tang, S.J. Interview from anywhere: feasibility and utility of web-based videoconference interviews in the gastroenterology fellowship selection process. Am J Gastroenterol 2014, 109, 155-159, doi:10.1038/ajg.2013.278.

14. Vadi, M.G.; Malkin, M.R.; Lenart, J.; Stier, G.R.; Gatling, J.W.; Applegate, R.L., 2nd. Comparison of web-based and face-toface interviews for application to an anesthesiology training program: a pilot study. Int J Med Educ 2016, 7, 102-108, doi:10.5116/ijme.56e5.491a.

15. Healy, W.L.; Bedair, H. Videoconference Interviews for an Adult Reconstruction Fellowship: Lessons Learned. J Bone Joint Surg Am 2017, 99, e114, doi:10.2106/jbjs.17.00322.

16. Barry, M.; Ghonem, L.; Alsharidi, A.; Alanazi, A.; Alotaibi, N.; Al-Shahrani, F.; Al Majid, F.; BaHammam, A. Coronavirus disease-2019 pandemic in the Kingdom of Saudi Arabia: Mitigation measures and hospital preparedness. Journal of Nature and Science of Medicine 2020, 3, 155-158, doi:10.4103/jnsm.jnsm_29_20.

17. Brueggeman, D.A.; Via, G.G.; Froehle, A.W.; Krishnamurthy, A.B. Virtual Interviews in the Era of COVID-19: Expectations and Perceptions of Orthopaedic Surgery Residency Candidates and Program Directors. JB JS Open Access 2021, 6, doi:10.2106/jbjs.oa.21.00034.

18. Hariton, E.; Bortoletto, P.; Ayogu, N. Residency Interviews in the 21st Century. J Grad Med Educ 2016, 8, 322-324, doi:10.4300/jgme-d-15-00501.1.

19. Robinson, K.A.; Shin, B.; Gangadharan, S.P. A Comparison Between In-Person and Virtual Fellowship Interviews During the COVID-19 Pandemic. J Surg Educ 2021, 78, 1175-1181, doi:10.1016/j.jsurg.2020.11.006.

20. D'Angelo, J.D.; D'Angelo, A.D.; Mathis, K.L.; Dozois, E.J.; Kelley, S.R. Program Director Opinions of Virtual Interviews: Whatever Makes my Partners Happy. J Surg Educ 2021, doi:10.1016/j.jsurg.2021.04.008.

21. Mohanty, A.; Caldwell, D.J.; Hadley, C.C.; Gibson, A.; Ravanpay, A.; Patel, A.J. Virtual Interviews in Neurosurgery Resident Selection-A Work in Progress. World Neurosurg 2021, doi:10.1016/j.wneu.2021.08.074.

22. Rajesh, A.; Asaad, M.; Elmorsi, R.; Ferry, A.M.; Maricevich, R.S. The Virtual Interview Experience for MATCH 2021: A Pilot Survey of General Surgery Residency Program Directors. Am Surg 2021, 31348211038555, doi:10.1177/00031348211038555.

23. Temsah, M.H.; Alkhattabi, F.; Aljamaan, F.; Alhasan, K.; Alherbish, A.; Philby, M.; Alsohime, F.; Alobaylan, M.; Alabdulkarim, H.; Almosned, B.; et al. Remote interviews for medical residency selection during the initial COVID-19 crisis: a national survey. BMC Med Educ 2021, 21, 462, doi:10.1186/s12909-021-02890-7.

24. Commissaris, C. Is My Mic Working? Audiovisual Quality Biases in the Virtual Residency Interview. In Acad Med; United States, 2021; Volume 96, pp. 615-616.

25. Sarac, B.A.; Calamari, K.; Janis, J. Virtual Residency Interviews: Optimization for Applicants. Cureus 2020, 12, e11170, doi:10.7759/cureus.11170.

\title{
Appendix:
}

\author{
Residency Application Feedback March 2020 cycle \\ Dear Colleague,
}

Thanks for your valuable participation in the Residency Application with SCFHS in March 2020.

We appreciate it if you can provide us your feedback on your videoconferencing in these interviews.

This is IRB approved proposal, that will also help us to optimize the videoconferencing for residents in the future. Continuing this survey is a consent from you to voluntary participate in this research.

This is an IRB-approved survey that will not be linked to you, and your voluntary participation can help us to further improve the process in the future. 


\section{Thanks and Be Safe!}

Dr. Hani Temsah mtemsah@ksu.edu.sa

Dr. Fadiah AlKhattabi fkhatabi@kfshrc.edu.sa

Dr. Basim Alsaywid drbasim@yahoo.com SCFHS Research Team

\section{1. To start the $\mathbf{5}$ minutes survey, please choose:}

I took part in the residency interviews of SCFHS residency application in 2020 and I agree to participate I do not agree to participate

\section{Demographics}

\section{* 2. You are:}

Faculty member Resident applicant Chief resident Coordinator

* 3. Prior to this Video Interview, did you have prior experience in this tool? No, my first time to use video conferencing

Yes I used video conferencing before, but first time to use it for residency interview

Yes I used video conferencing before, including for residency interview

* 4. The videoconferencing tool you used:

PC (laptop) PC (Desk top) Mobile

* 5 . What is your gender?

Female Male

* 6. Your residency application:

Pediatrics Family medicine Internal medicine Other (please specify) Surgery Emergency medicine Psychiatr

Faculty page:

* 7. How much did you find the video interview, as compared to previous traditional face-to-face interviews:

Strongly disagree Disagree Neither agree or disagree Agree Strongly agree

My questions for the candidates were answered

Strongly disagree Disagree Neither agree or disagree Agree Strongly agree

* 8 . Which video conferencing tool did you use? 
All through Face Time

Mostly Face Time, Few Zoom

Almost equal: Face Time and Zoom Other (please specify)

Mostly Zoom, Few Face Time All through Zoom

* 9. What factor(s) made you prefer one video conferencing tool over the other? (Please choose all that apply) My own personal preference (example: previous experience with Zoom or Face Time)

The candidates preference

The ease of use (user-friendly) of the App

My colleague's advice

My mobile operating system (Apple versus Android-based)

Other (please specify)

* 10. Number of your academic experience as consultant: less than 5 years 5 -10 years more than 10 years

Applicant's page:

* 11. Which video tool did you use in this interview:

Face Time Zoom Other (please specify)

* 12. How much did you find the video interview, as compared to previous traditional face-to-face interviews:

Strongly disagree Disagree Neither agree or disagree Agree Strongly agree

My questions about this residency program were answered adequately by the applicant

Strongly disagree Disagree Neither agree or disagree Agree Strongly agree

* 13. What factor(s) made you prefer one video conferencing tool over the other? (Please choose all that apply)

My own personal preference (example: previous experience with Zoom or Face Time)

The ease of use (user-friendly) of the App The committee preference

My colleague's advice 
My mobile operating system (Apple versus Android-based)

Other (please specify)

* 14. Approximately how much do you think this video interview (as compared to coming for face-to-face interview) saved you money in total (example: travel expenses, transportation, hotel accommodations...etc)

Less than $100 \mathrm{SR} \quad 100-500 \mathrm{SR}$ More than $500 \mathrm{SR}$

Chief Resident or Coordinator page:

* 15. How much did you find the video interview, as compared to previous traditional face-to-face interviews:

Disagree Disagree Neither agree or disagree Agree Strongly agree

My questions for the candidates were answered

Disagree Disagree Neither agree or disagree Agree Strongly agree

* 16. Which video conferencing tool did you use?

All through Face Time

Mostly Face Time, Few Zoom

Almost equal: Face Time and Zoom Other (please specify)

Mostly Zoom, Few Face Time All through Zoom

* 17. What factor(s) made you prefer one video conferencing tool over the other? (Please choose all that apply)

My own personal preference (example: previous experience with Zoom or Face Time)

The candidates preference The committee preference 
The ease of use (user-friendly) of the App My colleague's advice

My mobile operating system (Apple versus Android-based)

Other (please specify)

Satisfaction with the interview process:

* 18. How likely is it that you would recommend the video conferencing interviews to a friend or colleague?

NOT AT ALL LIKELY

EXTREMELY LIKELY

0

12

3

$4 \quad 5$

6

$\begin{array}{ll}7 & 8\end{array}$

9

10

* 19. Currently with the COVID19 Pandemic: How do you find Video Interviews as compared to face-to-face interviews?

Video Interviews are preferable Equally preferable Face-to-face interview are preferable

* 20. How much do you agree with the following statements regarding this video interview:

Disagree Disagree Neither agree or disagree Agree Strongly agree

- Video conferencing interviews decreased the costs for the candidates

21. Overall, how would you rate the event?

Excellent Very good Good Fair Poor

* 22. What factors improved your video conferencing interview? (please choose all that apply)

Organizers' communication

WhatsApp group discussion that related specifically to this event

Emails from the organizers

Demo of the video conferencing App before the event

Clear instructions

Free application (Zoom or Face Time) fast internet speed

Other (please specify) 
* 23. What factors negatively affected your video conferencing interview? (please choose all that apply)

WhatsApp group discussion that related specifically to this event

Not receiving the emails from the organizers

Not having Demo of the video conferencing App before the event

Unclear instructions

Videoconferencing tool / Application-related (for example: unfamiliar with Zoom or Face Time)

Slow or interrupted internet speed

Other (please specify)

24. How organized was the event?

Extremely organized Very organized Somewhat organized Not so organized Not at all organized

* 25. Prior to the event, how much of the information that you needed did you get?

All of the information Most of the information Some of the information A little of the information None of the information

* 26. Was the event length too long too short or about right?

Much too long Too long About right Too short Much too short

* 27. How much do you rate satisfaction with your videoconferencing in regards to:

Extremely satisfied Extremely unsatisfied Unsatisfied satisfied neither Satisfied nor unsatisfied

. Voice quality

. Your time management flexibility

. Battery/power supply issues

. Your place (office/hospital/home) flexibility

28. Is there anything else you'd like to share about the event?

29. Have you experienced any of the following symptoms immediately after your online video-interview experience?

\section{Never Almost never Sometimes Fairly Often Very Often}

. In the last month, how often have you felt that you were unable to control the important things in your life? 
. In the last month, how often have you felt confident about your ability to handle your personal problems?

. In the last month, how often have you found that you could not cope with all the things that you had to do?

. In the last month, how often have you felt that you were on top of things?

. In the last month, how often have you felt difficulties were piling up so high that you could not overcome them?

If you want to receive email updates on this research, please provide your email (it will not be linked with your answers) 